See discussions, stats, and author profiles for this publication at: https://www.researchgate.net/publication/307435935

\title{
Experimental and Analytical Assessment of the Capacity of Traditional Single Notch Joints and Impact of Retrofitting by Self-tapping Screws
}

Chapter · January 2016

DOI: 10.1007/978-3-319-39492-3_30

\section{CITATIONS}

6

6 authors, including:

Yasemin Didem Aktas

University College London

48 PUBLICATIONS 155 CITATIONS

SEE PROFILE

Izabela Burawska

Warsaw University of Life Sciences - SGGW

6 PUBLICATIONS 16 CITATIONS

SEE PROFILE

Some of the authors of this publication are also working on these related projects:

IPW2020 - 18th International Probabilistic Workshop View project

Project RILEM TC 245 RTE View project
Coralie Avez

Université de Mons

14 PUBLICATIONS 42 CITATIONS

SEE PROFILE

27 J.M. Branco

University of Minho

156 PUBLICATIONS 788 CITATIONS

SEE PROFILE 


\title{
Experimental and Analytical Assessment of the Capacity of Traditional Single Notch Joints and Impact of Retrofitting by Self-tapping Screws
}

\author{
Karel Šobra, Richard de Rijk, Yasemin D. Aktaş, Coralie Avez, \\ Isabela Burawska and Jorge M. Branco
}

\begin{abstract}
The joints are the most crucial parts of a timber building and determine the overall structural behaviour, load-bearing capacity and failure mechanisms. Therefore, keeping the joints fully functional is of utmost importance to ensure a desired structural performance of timber buildings under various actions. Since replacement of damaged parts of an existing structure is expensive and in many cases very difficult to perform in situ, retrofitting to avoid failure becomes an increasingly widespread strategy. In this paper, the capacity and failure mechanisms of single notch joints before and after a simple retrofitting intervention by means of self-tapping screws were investigated. To this end, a series of tests were carried out during the 5th COST FP 1101 Training School, held in University of Minho, Portugal. The joints were first tested under compression, and the load-bearing capacity values obtained at the end of tests were compared to the capacity values
\end{abstract}

\footnotetext{
K. Šobra (凹)

Czech Technical University in Prague, Thákurova 7, 16629 Prague 6, Czech Republic e-mail: karel.sobra@fsv.cvut.cz

R. de Rijk

Eindhoven University of Technology, 5612 AZ Eindhoven, The Netherlands

e-mail: r.j.c.w.d.rijk@student.tue.nl

Y.D. Aktaş

University College London, Gower Street, London, WC1E 6BT, UK

e-mail: y.aktas@ucl.ac.uk

C. Avez

University of Mons, Rue du Joncquois 53, 7000 Mons, Belgium

e-mail: coralie.avez@umons.ac.be

I. Burawska

Warsaw University of Life Sciences, Nowoursynowska 166, 02-787 Warsaw, Poland

e-mail: izaburawska@o2.pl

J.M. Branco

ISISE, University of Minho, Campus de Azurém, 4800-058 Guimarães, Portugal

e-mail: jbranco@civil.uminho.pt 
calculated using theoretical models proposed in a variety of national codes. Then, tested joints were retrofitted using self-tapping screws. The retrofitting strategy aimed to prevent failure mechanism that was shown to dominate joints' behaviour in the unreinforced state, rather than to increase the load-bearing capacity or stiffness. The impact of retrofitting on the joints' performance was discussed and the success of the proposed intervention was further debated.

Keywords Traditional carpentry joints - Single notch joints • Retrofitting • Self-tapping screws

\section{Introduction}

Joints play a crucial role in determining the overall structural behaviour, load-bearing capacity and failure mechanisms under various loading conditions including seismic action. Among various joints that can be observed in timber buildings around the world, traditional carpentry joints take an important place. Single notch joints, known also as step, framed or cogging joints, are among the most commonly used traditional carpentry joints. In [1, 2], the authors tested double and single notch joints under compression and rotation to characterize behaviour and develop strengthening solutions. In some studies, the behaviour of single joints was deducted from results obtained from the testing of an entire building, such as in [3] where a traditional roof structure was tested to elaborate more on the impact of diversely retrofitted connections on the overall structural behaviour under monotonic and cyclic loading. In [4, 5], number of single notch joints were tested without and with mortise and tenon fitting, and conclusions were drawn with regards to the reinforcement/repair techniques as well as geometrical configuration of the joints (i.e., notch depth, skew angle, etc.). In another study [6], finite element analyses of single notch joints were carried out and unrealistic assumptions in design codes were pointed out. In [7, 8], the authors investigated the impact of common strengthening techniques, such as tension ties and stirrups, on single notch joints with varying geometrical features by means of a series of monotonic/cyclic tests.

In this study, a single notch joint was tested under compression and the obtained capacity value was compared against the capacity calculated using analytical models proposed by various national codes. Then the tested joint was retrofitted using self-tapping screws. Unlike conventional interventions, the reinforcement strategy that was followed here aimed to prevent failure mechanism that was shown to dominate joint behaviour in the unreinforced state, rather than to increase the load-bearing capacity or stiffness. It was analysed how retrofitting affects the failure mechanism and the capacity of the joint. 


\section{Testing of the Unreinforced Joints and Stress Values on Contact Surfaces}

The tests described here were carried out during the 5th COST FP 1101 Training School that was held in University of Minho on 11-14 May 2015. The joints were first tested under compression (Fig. 1). For this aim, glued-laminated specimens with strength class GL $24 \mathrm{~h}$ were used (Table 1).

The unreinforced capacity under compression was measured as $42.5 \mathrm{kN}$ (Fig. 2a). Assuming a linear stress distribution in the contact areas of the connection, the force measured in the actuator can be decomposed into two components perpendicular to the contact planes (Fig. 1) and this component can be divided over the contact area to obtain theoretical stresses (Fig. 2b). As these stresses are perpendicular to the contact planes of the connection they are acting under an angle to the grain direction of the elements.

The maximum stress level on an angle to the grain can be obtained by several theories. This has been done with the theories of Norris [9], Hankinson [10] and by decomposing $\mathrm{f}_{\mathrm{c} ; 0}, \mathrm{f}_{\mathrm{c} ; 90}, \mathrm{f}_{\mathrm{v}}$ using the characteristic values for GL $24 \mathrm{~h}$. The maximum stress levels in the contact surfaces, being at a $30^{\circ}$ angle to the grain for the front-notch surface and $80^{\circ}$ for the bottom-notch surface (Fig. 1), are shown for different theories (Table 2) in Fig. 3. However, this plot is very conservative since the characteristic values for GL $24 \mathrm{~h}$ represent a statistical $5 \%$ lower limit of the materials strength
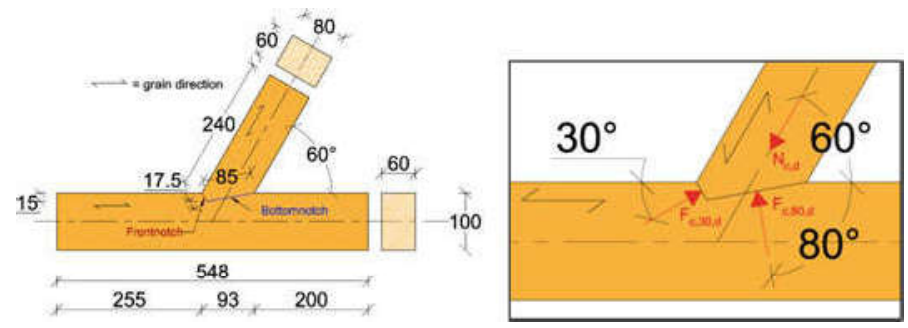

Fig. 1 Geometry of the tested Single notch joint

Table 1 Characteristic material properties of the test specimen (MPa)

\begin{tabular}{l|l|l|l|l}
\hline$f_{t ; 0 ; k}$ & $f_{t ; 90 ; k}$ & $f_{c ; 0 ; k}$ & $f_{c ; 90 ; k}$ & $f_{v ; k}$ \\
\hline 16.5 & 0.4 & 24 & 2.7 & 2.7 \\
\hline
\end{tabular}



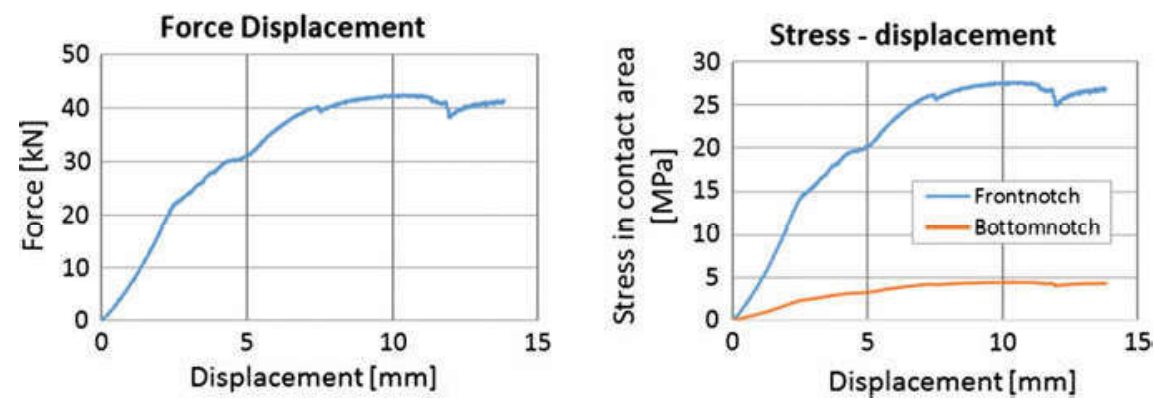

Fig. 2 (Left) Force displacement plot of the testing of single-notch joint, (right) Theoretical stress in the contact areas of the connection versus displacement of the actuator

Table 2 Stress values on contact surfaces according to a few theories

\begin{tabular}{|c|c|c|}
\hline $\begin{array}{l}\text { Hankinson } \\
\quad f_{c_{c} ;: k} * f_{c ;} ; 0 ; k \\
\end{array}$ & \multirow{2}{*}{\multicolumn{2}{|c|}{$\begin{array}{l}\text { Norris } \\
\frac{f_{c ; 0 ;}}{\cos \alpha^{2} * \sqrt{1+\left(\frac{f_{c} ; 0 ; k}{f_{v ; k}}\right)^{2} * \tan \alpha^{2}+\left(\frac{f_{c ; 0 ;}}{f_{c, 90 ; k}}\right)^{2} * \tan \alpha^{4}}}\end{array}$}} \\
\hline $\bar{f}_{c, 0 ; k ;} * \sin \alpha^{2}+f_{c, 90 ; k} * \cos \alpha^{2}$ & & \\
\hline $\mathbf{f}_{\mathbf{0}, \mathbf{c}} \frac{f_{c ; 0}, \cdot k}{\cos \alpha^{2}}$ & $\mathbf{f}_{\mathbf{9 0 ,}, \mathbf{c}} \frac{f_{c, 9}, 0 ; k}{\sin \alpha^{2}}$ & $\mathbf{f}_{\mathbf{v}} \frac{f_{v ; k}}{\sin \alpha * \cos \alpha}$ \\
\hline
\end{tabular}

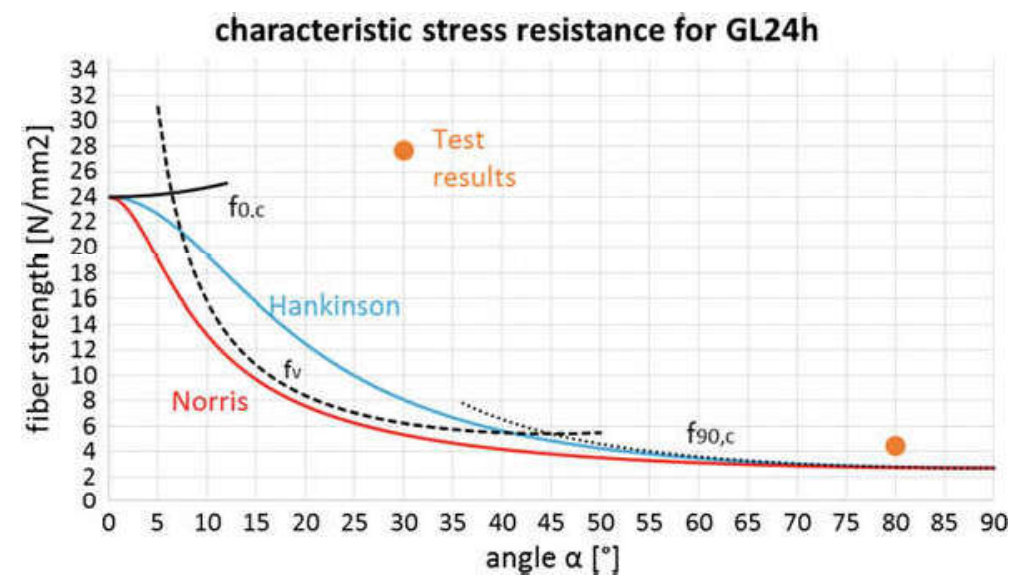

Fig. 3 Several theories giving material strengths when loading under an angle versus lab test results

\section{Capacity Calculation According to Various Codes}

As a uniform European standard on carpentry connections is not available, only national standards or national annexes containing guidelines for designing carpentry connections can be used for this purpose. In this study, the following three 


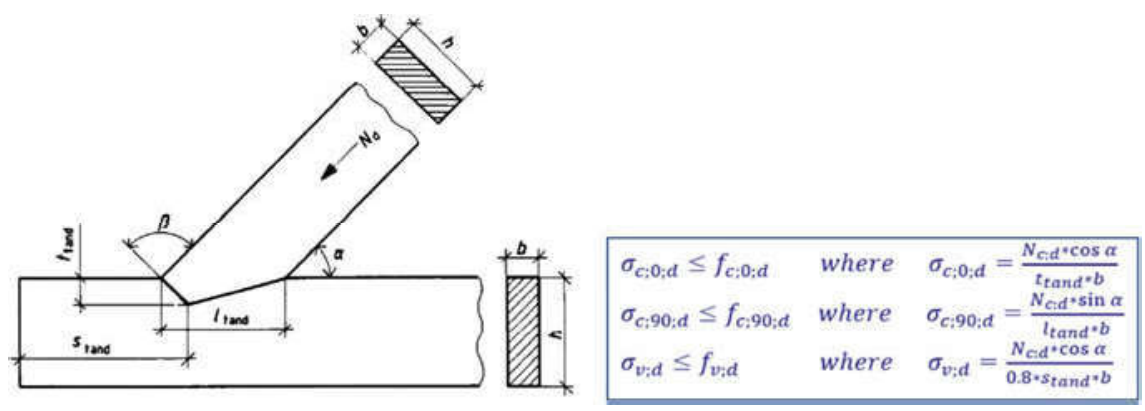

Fig. 4 Dutch national annex to NEN-EN 1995-1-1 on carpentry joints

national standards with different theoretical bases for determining maximum stresses in the contact areas were used:

1. Dutch national annex to NEN-EN 1995-1-1 [11] (Based on decomposition of forces)

The Dutch national annex to Eurocode 5 gives guidelines for maximum stress levels based on decomposing the force in the diagonal into components which act on the depth and length of the notch. For comparing the test results with the guidelines in the code, the specimen geometry and characteristic material strengths of GL $24 \mathrm{~h}$ are used to determine the maximal force $\mathrm{N}_{\mathrm{c} ; \mathrm{d}}$ according to the formulas in the Dutch code as shown in Fig. 4.

The obtained results are given below:

\begin{tabular}{l|l|l|l|l}
\hline $\mathrm{f}_{\mathrm{c} ; 0 ; \mathrm{k}} \rightarrow \mathrm{f}_{\mathrm{c} ; 0 ; \mathrm{d}}=\sigma_{\mathrm{c} ; 0 ; \mathrm{d}}=$ & $\alpha=60^{\circ}$ & $\mathrm{t}_{\text {tand }}=15 \mathrm{~mm}$ & $\mathrm{~b}=60 \mathrm{~mm}$ & $\begin{array}{l}\mathrm{N}_{\mathrm{c} ; \mathrm{d}}= \\
43.2 \mathrm{kN}\end{array}$ \\
\hline $\begin{array}{l}24 \mathrm{~N} / \mathrm{mm}^{2} \\
\mathrm{f}_{\mathrm{c} ; 90 ; \mathrm{k}} \rightarrow \mathrm{f}_{\mathrm{c} ; 90 ; \mathrm{d}}=\sigma_{\mathrm{c} ; 90 ; \mathrm{d}}=\end{array}$ & $\alpha=60^{\circ}$ & $1_{\text {tand }}=92.5 \mathrm{~mm}$ & $\mathrm{~b}=60 \mathrm{~mm}$ & $\begin{array}{l}\mathbf{N}_{\mathrm{c} ; \mathbf{d}}= \\
\mathbf{1 7 . 3} \mathbf{~ k N}\end{array}$ \\
\hline $\begin{array}{l}2.7 \mathrm{Nm} / \mathrm{mm}^{2} \\
\mathrm{f}_{\mathrm{v} ; \mathrm{k}} \rightarrow \mathrm{f}_{\mathrm{v} ; \mathrm{d}}=\sigma_{\mathrm{v} ; \mathrm{d}}=\end{array}$ & $\alpha=60^{\circ}$ & $\mathrm{s}_{\text {tand }}=263.5 \mathrm{~mm}$ & $\mathrm{~b}=60 \mathrm{~mm}$ & $\begin{array}{l}\mathrm{N}_{\mathrm{c} ; \mathrm{d}}= \\
68.3 \mathrm{kN}\end{array}$ \\
\hline
\end{tabular}

The lowest of all values obtained for $\mathrm{N}_{\mathrm{c} ; \mathrm{d}}$ is $17.3 \mathrm{kN}$ and it occurs for the $\mathrm{f}_{\mathrm{c} ; 90 ; \mathrm{k}}$ parameter. This force is approximately 2.5 times lower than $42.5 \mathrm{kN}$ measured in the lab test.

2. German national annex to DIN-EN 1995-1-1 [12] (Based on Norris's theory)

The German national annex to Eurocode 5 uses a derivation from Norris's theory to determine the maximum allowable stress under an angle to the grain. With the given formula, the maximum stresses in the front-notch and bottom-notch can be determined individually for different angles $\alpha$ of loading to the grain as shown in Fig. 5. 


$$
\begin{aligned}
& \text { Where: } \sigma_{c, \alpha, d}= \frac{F_{c, \alpha, d}}{A} \\
& f_{c, \alpha, d}=\frac{\sigma_{c, \alpha, d}}{f_{c, \alpha, d}} \leq 1 \\
& \sqrt{\left(\frac{f_{c, 0, d}}{2 \cdot f_{c, 90, d}} \sin ^{2} \alpha\right)^{2}+\left(\frac{f_{c, 0, d}}{2 \cdot f_{v, d}} \sin \alpha \cdot \cos \alpha\right)^{2}+\cos ^{4} \alpha}
\end{aligned}
$$

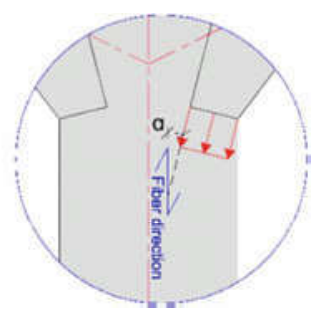

Fig. 5 German national annex to DIN-EN 1995-1-1 on carpentry joints

\begin{tabular}{l|l|l|l|l}
\hline Front-notch & $\alpha=30^{\circ}$ & $\mathrm{A}=17.5 * 60 \mathrm{~mm}^{2}$ & $\begin{array}{l}\mathrm{f}_{\mathrm{c} ; 30 ; \mathrm{d}}=\sigma_{\mathrm{c} ; 30 ; \mathrm{d}}= \\
10.23 \mathrm{MPa}\end{array}$ & $\begin{array}{l}\mathrm{F}_{\mathrm{c} ; 30 ; \mathrm{d}}= \\
\mathbf{1 0 . 7} \mathbf{k N}\end{array}$ \\
\hline Bottom-notch & $\alpha=80^{\circ}$ & $\mathrm{A}=84.8 * 60 \mathrm{~mm}^{2}$ & $\begin{array}{l}\mathrm{f}_{\mathrm{c} ; 80 ; \mathrm{d}}=\sigma_{\mathrm{c} ; 80 ; \mathrm{d}}= \\
5.48 \mathrm{MPa}\end{array}$ & $\begin{array}{l}\mathrm{F}_{\mathrm{c} ; 80 ; \mathrm{d}}= \\
27.9 \mathrm{kN}\end{array}$ \\
\hline
\end{tabular}

Decomposing the force of $42.5 \mathrm{kN}$ obtained at the end of testing into the same angular components of $30^{\circ}$ and $80^{\circ}$ (Fig. 1) give $F_{c ; 30 ; d}=29 \mathrm{kN}$ and $F_{c ; 80 ; d}=$ $22.6 \mathrm{kN}$, which means that the maximum allowable force in the front-notch is lower than the tested force and thereby governing $(29 \mathrm{kN}>10.7 \mathrm{kN})$.

3. Swiss SIA 265 [13] (Based on Hankinson's theory)

The Swiss code uses a slightly altered version of Hankinson's equation to determine maximal stresses at an angle. These results are used to calculate the minimal dimension of the connection, but since these are already determined by the test specimens, again a maximal force in the diagonal (named $F_{E d}$ in the Swiss formula's, see Fig. 6) can be determined.
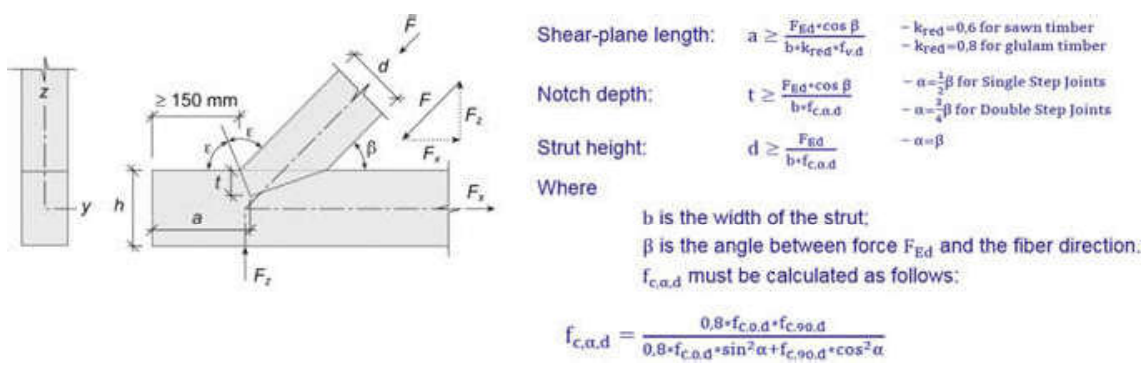

Fig. 6 Swiss SIA 265 on carpentry joints 
The obtained results are given below:

\begin{tabular}{l|l|l}
\hline Using a & Using $\mathrm{t}$ & Using $\mathrm{d}$ \\
\hline$\beta=60^{\circ}$ & $\beta=60^{\circ}$ & $\mathrm{b}=60 \mathrm{~mm}$ \\
$\mathrm{~b}=60 \mathrm{~mm}$ & $\mathrm{~b}=60 \mathrm{~mm}$ & $\mathrm{f}_{\mathrm{c} ; ; ; \mathrm{d}}=7.59 \mathrm{MPa}$ \\
$\mathrm{k}_{\mathrm{red}}=0.8$ & $\mathrm{f}_{\mathrm{c} ; \alpha ; \mathrm{d}}=7.59 \mathrm{MPa}$ & $\mathrm{d}=80 \mathrm{~mm}$ \\
$\mathrm{f}_{\mathrm{v} ; \mathrm{d}}=2.7 \mathrm{MPa}$ & $\mathrm{t}=15 \mathrm{~mm}$ & \\
$\mathrm{a}=263.5 \mathrm{~mm}$ & & \\
\hline $\mathrm{F}_{\mathrm{Ed}}=68.3 \mathrm{kN}$ & $\mathrm{F}_{\mathrm{Ed}}=\mathbf{1 3 . 7} \mathbf{~ k N}$ & $\mathrm{F}_{\mathrm{Ed}}=\mathbf{3 6 . 4} \mathbf{k N}$ \\
\hline
\end{tabular}

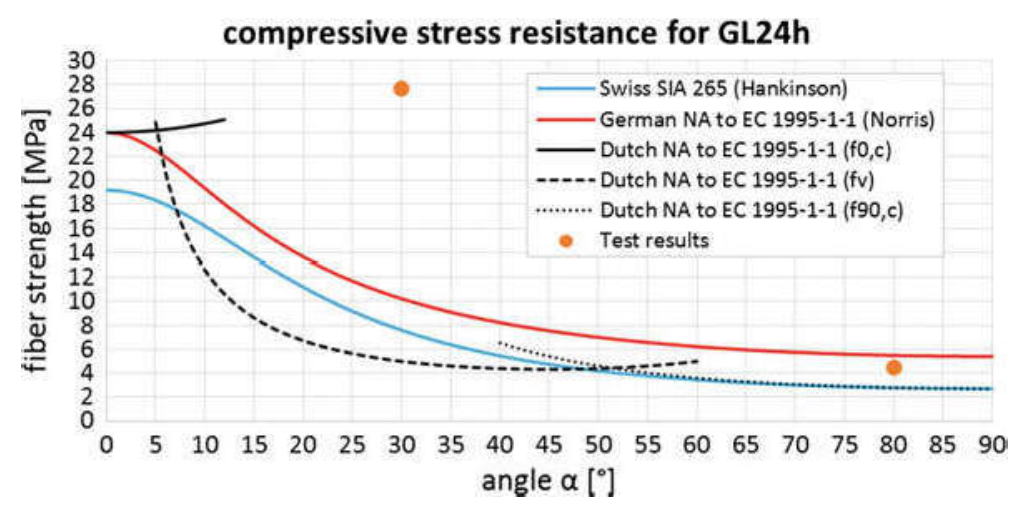

Fig. 7 Test results versus national standards

The formulas for $t$ and $d$ give smaller maximal forces than the applied force of $42.5 \mathrm{kN}$ in the lab test, with $\mathrm{t}$ being governing since it gives the lowest allowable normal force in the diagonal.

The maximum allowable stress under an angle according to these codes can also be plotted for loading angles between $0^{\circ}$ (parallel to the grain) and $90^{\circ}$ (perpendicular to the grain) together with the results of the scaled lab test (Fig. 7).

\section{Retrofitting Front Notch Joint Against Particular Failure Nodes}

A variety of retrofitting/strengthening techniques are used to alter the failure mechanism or increase the load-bearing capacity or stiffness of traditional carpentry joints and structures built by these. Among the most commonly used techniques is the use of internal or external metal connectors such as stirrups, bolts, binding strips, clamps, glued-in rods and tension ties (e.g., [14-17]). In addition to these, self-tapping screws have been increasingly widespread in the last decade, as they 

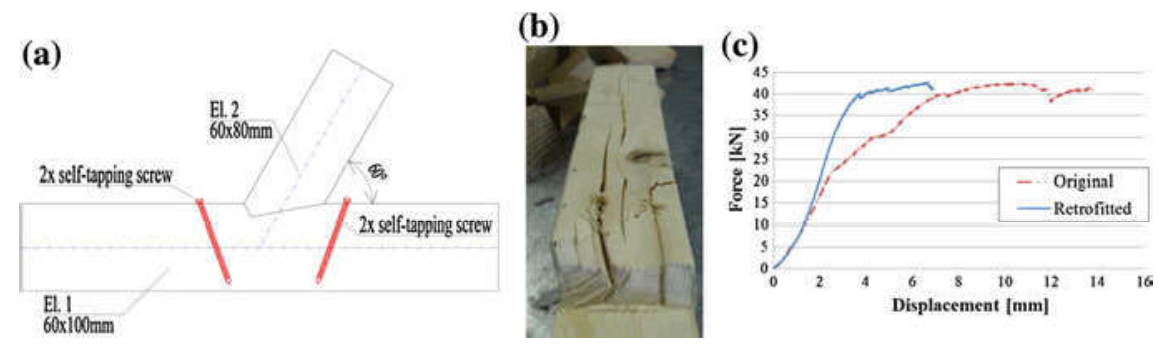

Fig. 8 Technique 1-reinforcement against shear failure of heel: a retrofitting with self-tapping screws, $\mathbf{b}$ obtained failure and $\mathbf{c}$ force displacement relationship from loading cell for both original and retrofitted joint

prevent connected elements from getting detached from each other and alter the load-path, hence the failure mode [17]. Self-tapping screws help joints become stiffer and result in an increase in the load-bearing capacity at low cost when used with care $[18,19]$.

One of the most common failure modes of front notch joints is shear failure in the heel. To avoid this failure, already tested joint was retrofitted at the heel by couple of self-tapping screws that were $100 \mathrm{~mm}$ in length and $8 \mathrm{~mm}$ in diameter (Fig. 8).

However, placing the screws without predrilling caused cracks on the upper surface of the joint (Fig. 8b). Even if the obtained failure mechanism looks like the joint experienced shear failure, it is the initial cracking due to the screws that caused delamination of wood where the crack follows annual ring. Despite these problems, the load bearing capacity of the joint remained more or less the same, but the average stiffness increased by approximately $50 \%$ (Fig. 8c). Thanks to the geometry of the joint, where two elements are connected under angle of $60^{\circ}$, shear failure was not observed but the joint was damaged just by compression of contact surfaces.

Then, retrofitting with self-tapping screws was repeated with two different geometrical configurations. Firstly, the screws were used to retrofit only the contact area of horizontal element (Fig. 9a). The post-elastic bearing capacity obtained following this retrofitting work was almost equal to the original one, however not only the average but also the initial stiffness in the linear range was almost half of the initial state (Fig. 9c).

Finally, in order to increase both the stiffness of the joint as a whole and its bearing capacity and also to minimize influence of large compressive deformations, contact areas of both elements have been reinforced using self-tapping screw (Fig. 10a). The bearing capacity of unreinforced joint was reached, however a sudden failure was observed by cracking that follows the annual ring.

At force displacement relationships of both types of reinforcement of contact areas is possible to see that those interventions are effective in terms of overall capacity of the joint, although lower stiffness and higher deformation were observed what could cause secondary problems in a truss construction. 
(a)

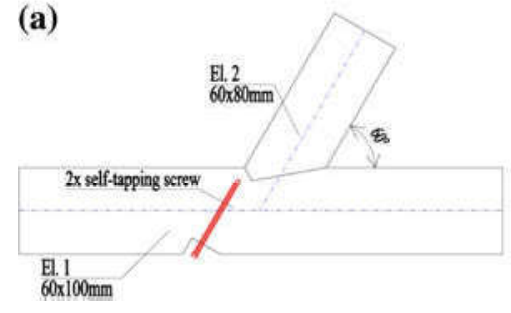

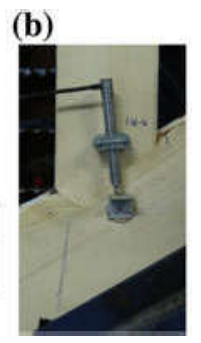

Fig. 9 Technique 2-reinforcement of horizontal element contact area: a retrofitting with self-tapping screws, b obtained failure and $\mathbf{c}$ force displacement relationship from loading cell for both original and retrofitted joint

(a)
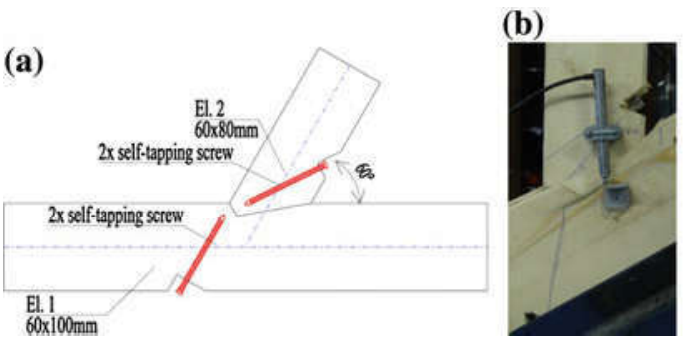

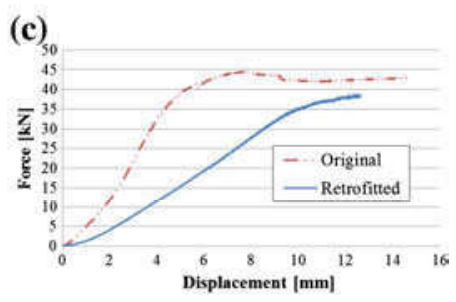

Fig. 10 Technique 3-reinforcement of contact areas of both elements: a retrofitting with self-tapping screws, $\mathbf{b}$ obtained failure and $\mathbf{c}$ force displacement relationship from loading cell for both original and retrofitted joint

\section{Discussion}

In this study, the load bearing capacity of a front notch joint of given geometry and dimensions under monotonically applied compression was measured between 38 and $45 \mathrm{kN}$. The specimen deformed plastically in both contact areas, and local shear failure (on one side only) was observed due to a knot very near to the notched area. Shear failure of the notched joint caused brittle failure of the connection, not allowing a large plastic yield deformation. Then the load bearing capacity was calculated using three different national codes, and it was seen that, among all codes that were used, the German National Annex to Eurocode 5 gives the least conservative values. This can be explained by the use of an amplification factor equal to 2, applied on the characteristic shear resistance of the material as well as the characteristic perpendicular-to-grain compressive resistance. These parameters, when doubled using the above-mentioned amplification factor, gives quite different results than the Dutch National Annex to Eurocode 5 and the Swiss SIA, which uses a factor of 0.8 to reduce characteristic shear capacity and parallel-to-grain compressive strength. However, despite this difference, all national codes seem to result in a significant underestimation of the joint capacity for low angle values. 
Then already tested joints were retrofitted using self-tapping screws in three different configurations. The first technique (Fig. 9) was used for the aim of preventing shear failure. By means of this intervention, the original load-bearing capacity and the initial stiffness of the unreinforced joint was reached, however shear failure was not efficiently prevented. In the second and third techniques, the original load-bearing capacity was almost reached, while the initial and overall stiffness (stiffness of a joint as a whole) of the joint significantly dropped. This behaviour may be caused partly by weakening of retrofitted cross-section, which was caused by preparing the surface to drill the screws to the required position and under required angle (slots seen on bottom parts of skew element at Figs. 8 and 9 and also at vertical element at Fig. 9) and partly that tested specimens already reached their elastic bearing capacity.

\section{Conclusion}

The international or European codes do not provide means to calculate capacity of traditional carpentry joints. Only a few national annexes suggest analytical approaches to calculate the capacity of front notch joints. However, three of these national codes that were examined as part of this study, i.e., German and Dutch National Annexes to Eurocode 5 as well as Swiss SIA, seem to significantly underestimate the capacity, therefore the need for revisiting the underlying assumptions and fine-tuning these methods to successfully reproduce the capacity of front notch joints is apparent. Also, it was concluded that the efficiency of retrofitting front notch joints using self-tapping screws should be further investigated, as the tests showed that this intervention can significantly reduce the initial and overall stiffness of a joint as a whole.

Acknowledgments The authors are grateful to COST Action for funding the FP1101 and RILEM 245 Training School at University of Minho in Guimarães, Portugal, and to Dr. Jorge M. Branco and other members of Civil Engineering Department for making this study possible.

\section{References}

1. Parisi MA, Cordie C (2010) Mechanical behaviour of double-step timber joints. Constr Build Mater 24(8):1364-1371

2. Parisi MA, Cordie C, Piazza M (2008) Seismic strengthening of carpentry joints in traditional timber structures. In: AIP conference proceedings, CP1020, 2008 seismic engineering conference commemorating the 1908 Messina and Reggio Calabria earthquake

3. Parisi MA, Piazza M (2002) Seismic-behavior and retrofitting of joints in traditional timber roof structures. Soil Dyn Earthq Eng 22(9-12):1183-1191

4. Palma P, Cruz H (2007) Mechanical behaviour of traditional timber carpentry joints in service conditions-results of monotonic tests. In: ICOMOS IWC-XVI international symposium: 
from material to structure-mechanical behaviour and failures of the timber structures. Florence, Venice, Vicenza

5. Palma P, Garcia H, Ferreira J, Appleton J, Cruz H (2012) Behaviour and repair of carpentry connections-rotational behaviour of the rafter and tie beam connection in timber roof structures. J Cult Heritage 13(3):S64-S73

6. Villar JR, Guaita M, Vidal P, Arriaga F (2007) Analysis of the stress state at the cogging joint in timber structures. Biosyst Eng 96(1):79-90

7. Branco J (2008) Influence of the joints stiffness in the monotonic and cyclic behaviour of traditional timber trusses-assessment of the efficacy of different strengthening techniques. Universidade do Minho, Guimarães

8. Branco JM, Piazza M, Cruz P (2011) Experimental evaluation of different strengthening techniques of traditional timber connections. Eng Struct 33(8):2259-2270

9. Norris CB (1962) Strength of orthotropic materials subjected to combined stresses. USBA, Wisconsin

10. Hankinson RL (1921) Investigation of crushing strength of spruce at varying angles to the grain. Air Serv Inf Circ. 3(259)

11. NEN (2013) NEN-EN 1995-1-1 Dutch NA 8.11 Ambachtelijke verbindingen. Nederlands Normalisatie-Instituut, Delft, pp 12-16

12. DIN (2010) DIN-EN-1995-1-1 German NA 12.1 Versätze. DIN Deutsches Institut für Normung, Berlin, pp 88-89

13. SIA (2012) Schweizer norm SIA 265-Holzbau. SIA, Zürich, pp 77-78

14. Branco J, Cruz P, Piazza M, Varum H (2006) Experimental analysis of original and strengthened traditional timber connections. In: 9 th world conference on timber engineering, Portland

15. Branco JM, Piazza M, Cruz PJS (2011) Experimental evaluation of different strengthening techniques of traditional timber connections. Eng Struct 33:2259-2270

16. Palma P, Garcia H, Ferreira J, Appleton J, Cruz H (2012) Behaviour and repair of carpentry connections - rotational behaviour of the rafter and tie beam connection in timber roof structures. J Cult Heritage 13:S64-S73

17. Branco J, Descamps T (2015) Analysis and strengthening of carpentry joints. Constr Build Mater (in press)

18. Dietsch P, Brandner R (2015) Self-tapping screws and threaded rods as reinforcement for structural timber elements-a state-of-the-art report. Constr Build Mater (in press)

19. Lathuillière D, Bléron L, Descamps T, Bocquet J-F (2015) Reinforcement of dowel type connections. Constr Build Mater (in press) 